\title{
Mathematical analysis of synthetic bulk density logs around the world- Part II- the use of non-linear regression
}

\author{
Mayra D. L. Carrasquilla, Marcus. Danilo F. B. Costa, Caique P. Carvalho, Igor J. S. Souza, José J. S. de Figueiredo, Carolina \\ B. da Silva, Carlos E. Amanajas, Celso Rafael Lima, João Rafael S. Silveira and L. Rautino (Federal University of Pará - \\ CPGF)
}

\section{Copyright 2021, SBGf - Sociedade Brasileira de Geofísica}

This paper was prepared for presentation during the $17^{\text {th }}$ International Congress of the Brazilian Geophysical Society, held in Rio de Janeiro, Brazil, 16-19 August 2021.

Contents of this paper were reviewed by the Technical Committee of the $17^{\text {th }}$ International Congress of The Brazilian Geophysical Society and do not necessarily represent any position of the SBGf, its officers or members. Electronic reproduction or storage of any part of this paper for commercial purposes without the written consent of The Brazilian Geophysical Society is prohibited.

\begin{abstract}
The bulk density is a helpful petrophysics parameter, which is used in the hydrocarbon oil exploration and another geophysics's areas as gravimetry and seismic. In this second part of the research we applied a nonlinear regression on determining the coefficients of a empirical nonlinear model. The nonlinear model analyzed was the modified Gardner's traditional model modified by Oloruntobi and Butt. Here, the inversion was performed based on Levenberg-Marquardt method. The linear and nonlinear methods are then compared, observing the influence of geological age, geological, geophysical and tectonic factors of the rocks on the mathematical and physical aspects. The analysis of models proposed by the different authors studied, it was made to determine the most efficient mathematical regression for the construction of density logs. The density was estimated from the of $V_{S H}$ and $V_{P}$ for Oloruntobi and Butt formulation. The study results show that it is impossible to determine a stable value for the parameters (either in the linear or nonlinear model) that can be applied to wells anywhere on the planet. The value of the parameters is affected by different factors that change according to the rock's content and the conditions that affect the study area. However, it is possible to determine values for a specific study zone with a margin of error of $<1 \%$ (mean square error). This error is lower than compared with results from linear regression results.
\end{abstract}

\section{Introduction}

From the geological point of view, the density rock property is generally used to identify rock types, and in the geochronological approach, rock density is a physical property that changes with geological time, pressure, and temperature (Fraser et al., 1997). In a geophysical context, rock density measurement arises from methods (gravimetry and well-logging, e. g.) that provide its values in different scales (Akimova and Misilov, 2020; Lindseth, 1979). From mathematics, empirical relations are frequently used within geophysics to obtain the density from seismic and seismological physical parameters (e. g., from $V_{P}, V_{S}$, Poisson ratio, Etc.). However, for empirical equations to be created- using linear or non- linear regressions- a data set (for a physical property of interest) from direct measurements is necessary to validate the mathematical method. Usually, for density in the seismic scale, the empirical density equations are calibrated from density well-log. Beyond that in the seismic scale does not provide the direct measurement of density, and the density log is frequently affected by wellbore environments effects, such as enlargement or shrinkage of the borehole wall and mud infiltration (de Macedo et al., 2019). Many authors proposed linear (Gardner et al., 1974a) and non-linear (Oloruntobi and Butt, 2019) empirical mathematical equations for the calculation of bulk density from other logs $\left(V_{P}\right.$, porosity, gamma-ray, and other logs) measured in the well. However, several approaches to this subject do not consider their models, variable depending on the present lithology, nor do they consider intrinsic factors of the rocks and external factors (e. g., weathering) that generate a preliminary or reliable estimative of the rocks' bulk density.

In part one of this study, Carrasquilla et al. (2020) showed - among several physical factors studied - the influence of the geological and tectonic factors and the geological age of the rocks, being applied on linear mathematical models proposed by different authors (Gardner et al., 1974a; Brocher, 2008; Lindseth, 1979). In this second part of our investigation, we continue analyzing all the factors mentioned above in the empirical equation, now obtained by non-linear regression. More specifically, we applied non-linear regression on the mathematical model proposed by Oloruntobi and Butt (2019) and, to solve this non-linear least-squares problem; it was used the Levenberg-Marquardt algorithm (LMA). Here, we applied our methodology in the same data set used in the part one of Carrasquilla et al. (2020).

\section{Theoretical Background}

The Gardner et al. (1974b)'s equation is given by

$$
\rho_{b}=k V_{P}^{b}
$$

where $\rho_{b}$ is the bulk density, $V_{P}$ is P-wave velocity and $k$ and $b$ are constants that can be determined by linear regression.

Oloruntobi and Butt (2019) proposed a modification of equation (1) taking into account the shale contribution. Their mathematical representation for a modified Gardner et al. (1974b)'s equation is given by

$$
\rho_{b}=A\left[V_{P}+G V_{s h}\right]^{m},
$$

where $V_{P}$ is the compressional wave velocity, $V_{s h}$ corresponds to the clay volume fraction and $(A, G, m)$ are 
constants.

In their work, Oloruntobi and Butt (2019) determined the values for $A, G$ e $m$ parameters using experimental values obtained Han et al. (1986). These values were: $A=1.350$, $G=1.651$ and $m=0.39$. In the case of experimental data, Han et al. (1986) studied 75 samples from the Gulf of Mexico. As we show in Carrasquilla et al. (2020), empirical parameters depend on geological formation. As it can be observed, the equation (2) is non-linear. To find their parameters, we need to use a numerical inversion method to solve the non-linear problem.

\section{Levenberg-Marquardt inversion method}

We chose the Levenberg-Marquardt (Levenberg, 1944; Marquardt, 1963) numerical method use to solve the equation (2). This method is a modification of the GaussNewton algorithm, which can be expressed in terms of the Jacobian $J_{f}$ of a function $f$ is:

$$
\alpha^{(s+1)}=\alpha^{(s)}+\left(\mathbf{J}_{\mathbf{f}}^{\top} \mathbf{J}_{\mathbf{f}}\right)^{-1} \mathbf{J}_{\mathbf{f}}^{\top} \mathbf{r}\left(\alpha^{(s)}\right)
$$

where $\alpha$ is the variable set correspondent to the iteration $s$. The term $r$ is the residual function. The operation $\mathbf{J}_{\mathbf{f}}^{\top}$ is the transpose of Jacobian $J_{f}$.

\section{Method}

The workflow of our case study is divided into four (4) steps. Its description is pictured in Figure 1. According to the first step, we started selecting well-logs data set from five (5) regions spread in different locations on the Earth. Here, the well-logs data analysed are from Taranaki (New Zealand), Niger Delta (Nigeria), Alaska National Oil Reservoir (USA), Teapot Dome (USA), Viking Graben (the North Sea - Norway), and Campos Basin (Brazil) oil fields (see Figure 2 in Carrasquilla et al. (2020)). The second step started from a processing and correction of well-logs. Here, we removed the aleatory noise elimination by a despiking procedure and a mud infiltration correction on the density log (based on the caliper log variations). Also, we analysed the effect of the processing-correction on the coefficients of the empirical model. More details about the sale volume estimation and mud infiltration correction and volume shale estimation are showed in Carrasquilla et al. (2020).

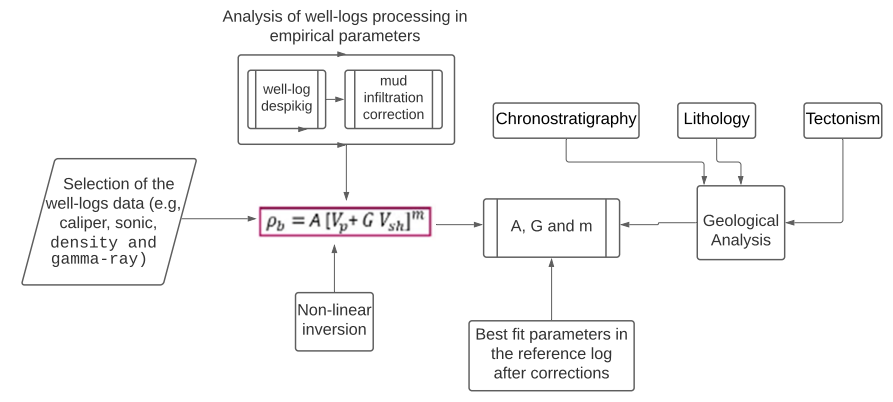

Figure 1: The flow chart showing the work methodology used the second part of this study. As it can be seen, the methodology is divided in four steps.

The step three (3) (see Figure 1) consists in a analysis of empirical parameters of equations (1) and (2) in a context of a geological analysis (chronostratigraphy, litology and tecnonism). The regression coefficients were obtained for reference well (Ariki) and oil field (Taranaki). Here, we found the nonlinear empirical model for this well. It is worthy to mention that, this well was selected because it has a wide range of geological ages. Finally, is the step four (4) we extended our empirical model for the well located in different oil field in the Earth. In addition to compare with the same analysys perfomed in Carrasquilla et al. (2020) for linear regressions.

For the implementation of the Levenberg-Marquardt algorithm, a computer code was built using the Matlab programming language. Wells from the Taranaki (New Zealand), Niger Delta (Nigeria), Alaska National Oil Reservoir (USA), Teapot Dome (USA), Viking Graben (North Sea - Norway) and Campos Basin (Brazil) oil fields were evaluated. Initially, the variation in the value of the resulting parameters is determined by applying corrections to the raw density, gamma-ray and $\mathrm{P}$-wave velocity data (calculated from the sonic log (feet/microseconds)) measured downhole with the application of the despike correction to each log used and the mud filtrate correction directly to the density log.

\section{Results}

The parameter values obtained by applying the non-linear regression inversion using and testing the well logs of the different fields mentioned above, show an inverse proproportional behavior between the $A$ and $m$ parameters and the $G$ parameter varies independently, altering according to the clay content recorded in the $V_{s h}$ log. After being applied the corrections, the $G$ parameter under the despike correction and the mud filtrate correction presents a noticeable decrease with respect to its original value. The parameters $A$ and $m$ continue acting inversely proportional, however, under the application of the corrections their values do not show abrupt variations, generating an increase or reduction $\leq 2.0 \%$ with respect to the value of the parameters obtained with the original data, as it is observed in Figure 2.

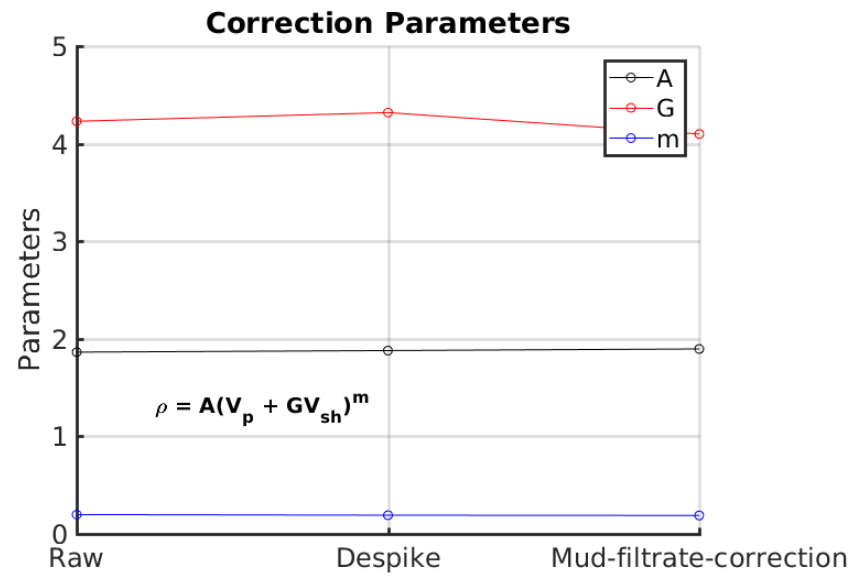

Figure 2: Graph of variation of the values of the parameters "A, $G$ and $\mathrm{m}$ " in the non-linear regression under the influence of the despike correction on the logs involved in the equation and the mud filtrate correction on the density log, evaluating for this case the data of the NRPA well ID 5002320012000 as a sample. 
Using all the data from the wells of each oil field to obtain the parameters, the parameter values that generated the greatest adjustment within the same oil field were selected. The reference parameters of each field were used to estimate an individual synthetic bulk deity log taking the Ariki well of the Taranaki field as the reference or base well. Figure 3 shows the coupling of each bulk density synthetic log with the original bulk density log of the Ariki well.

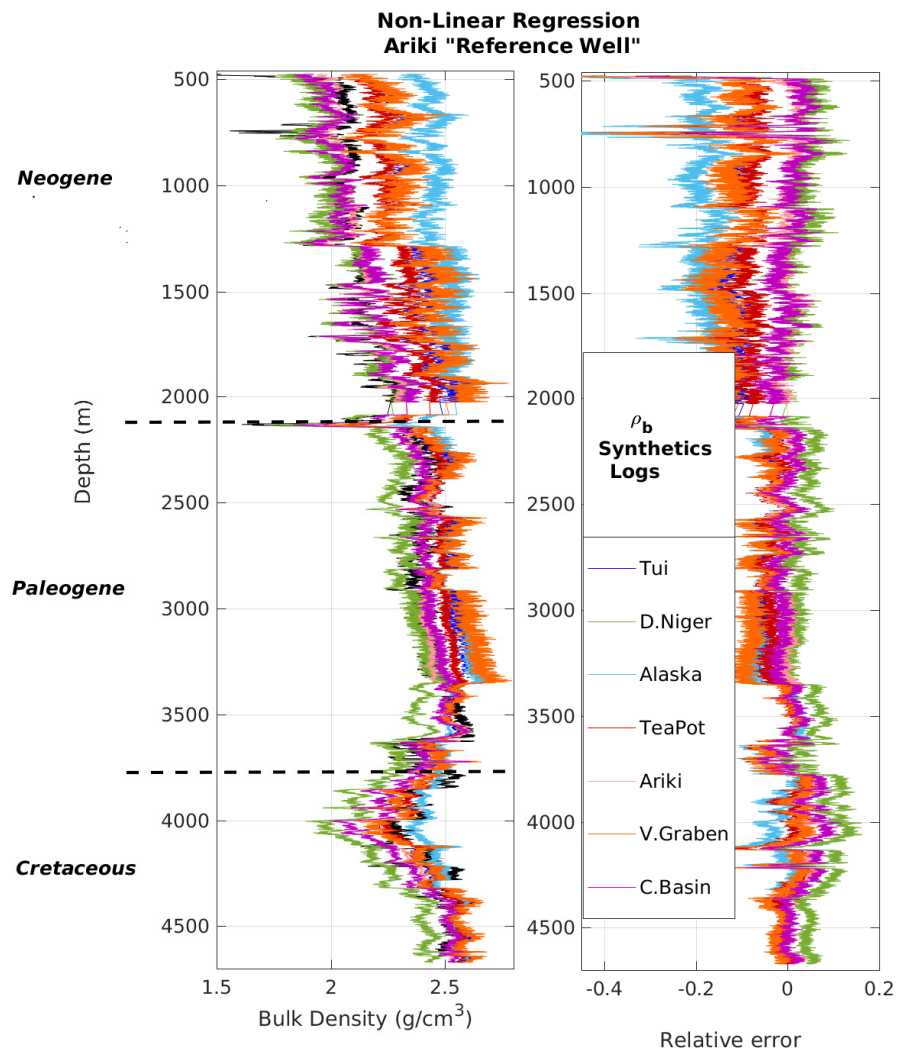

Figure 3: Synthetic bulk density logs from the Ariki well (taranaki basin oil field) using calculated parameters of the NPR Alaska, Teapot Dome, Viking Graben (Norway), The Campos Basin (Brazil) and Taranaki - New Zaland (Tui and Ariki) oil fields in the non-linear equation proposed by Oloruntobi and Butt (2019)

Tabela 1: Table of mean squared errors (MSE) of each bulk density log calculated with the parameters of different fields and applied to the ariki well, using the Non-Linear regression equation 1 proposed by Oloruntobi and Butt (2019)

\begin{tabular}{|c|c|}
\hline Synthetic Logs & $\begin{array}{c}\text { (MSE) Non-Linear } \\
\text { Regression } \\
\rho_{b}=A\left[V_{P}+G V_{s h}\right]^{m}\end{array}$ \\
\hline Ariki & 0.0047 \\
Tui & 0.0321 \\
NPRA & 0.0712 \\
Teapot Dome & 0.0178 \\
Viking Graben & 0.0393 \\
Campos Basin & 0.0065 \\
Delta Niger & 0.0175 \\
\hline
\end{tabular}

Using information from seismic surveys conducted in the Taranaki field in New Zealand released in Strong et al. (2012), the results of the different synthetic logs estimated for the Ariki well are analyzed with transects on which the Tui and Ariki wells are essentially located (transect 7 and 5 respectively) Figure 4, which contain a geochronological (geological age) interpretation from geological-geophysical studies made in the Taranaki oil field, delimiting the seismic transect at times according to the age of the rock bodies present, being illustrated in Figure 5 and Figure 6.
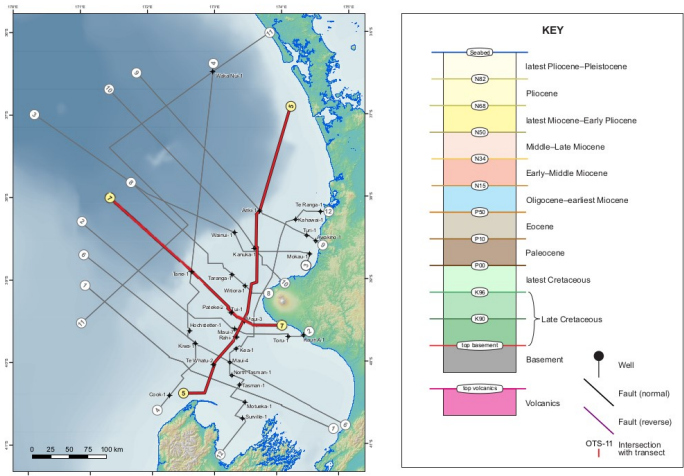

Figure 4: Regional offshore seismic map from Taranaki oil field, which shows the seismic transets made on the zone, highlighting with red color the transets used within of the study (five and seven transets). To the right side from the figure is the legend or key that describes the nomenclature used for the geochronological interpretation on the seismic transets. Source: (Strong et al., 2012)

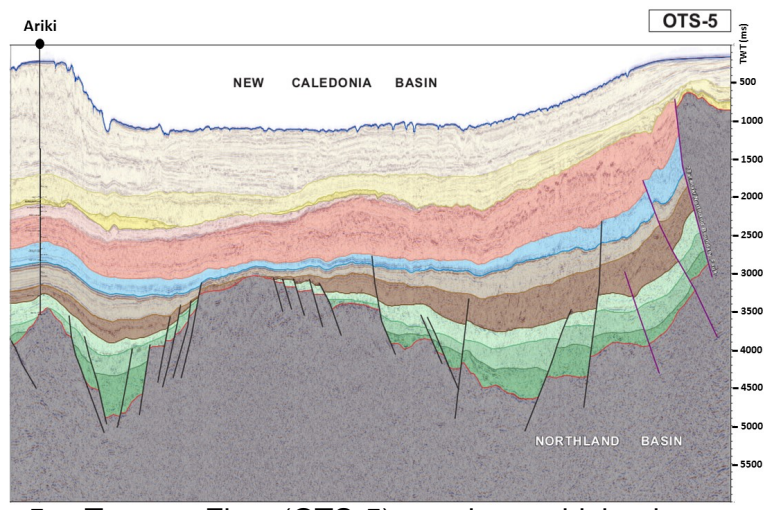

Figure 5: Transet Five (OTS-5) section, which shows geochronological intepretation on the seismic lines: dtb0 1-34 (SW-NE) and cnl95b-003 (SSW-NNE). The Ariki well is located on dtb0 1-34 seismic line. Source: Strong et al. (2012)

As it was verified in the first part of this paper, the application of the Despike correction on the logs used within the nonlinear regression $\left(V_{P}, V_{s h}\right.$ and $\left.\rho_{b}\right)$ and the mud filtrate correction directly on the $\rho_{b}$ log, also infer that the parameters found by inversion applying the Levenberg-Marquardt algorithm have more control over the dispersion and distribution of data when used for bulk density estimation, making by itself an intrinsic correction that generates a cleaning of noises present within the data and increasing the veracity of the results and increasing the security of the implementation of the parameters obtained 


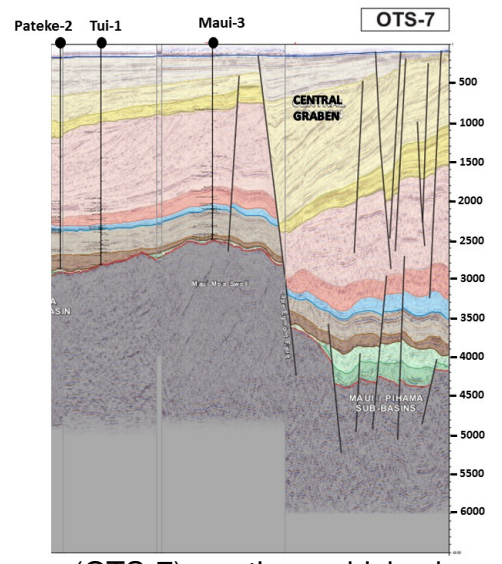

Figure 6: Transet seven (OTS-7) section, which shows geochronological intepretation on the seismic lines: sunz91-165 (NE-SW), stos95-212 (NW-SE), f19-549(W-E), 86ma-058 (NW-SE) and hzt82a-144 (W-E). The Tui-1 well is located on stos95-212 seismic line. Source: Strong et al. (2012)

under the method proposed and corrections applied.

The parameters determined using the non-linear model proposed by Oloruntobi and Butt (2019), show a more defined reproduction with greater dispersion of data, allowing to distinguish more easily some local geological and tectonic characteristics of the rocks present through the comparison of the density logs of the different studied fields. By reproducing the same well (reference well) using the parameters obtained from the different oil fields implemented within the study, different bulk density synthetic logs are obtained with partially different data distributions, where some reproductions do not generate over-positioning of the synthetic log with respect to the original density log as shown in Figure 3. The parameters that generated a greater approximation to the density log taken as a basis (Ariki raw) are those obtained using the data from the Ariki well and the Tui well, which belong to the same oil field. Previously, it was showed that, although finding the parameters with the non-linear regression generates a greater approximation of the synthetic density logs to the original density log -in comparison to the linear methods studied in the first part-, there is still interference from other aspects inherent to each field, such as geology, tectonics, geology age, weathering effects and other geological-environmental aspects that cause interference as studied in the first part of this article.

By evaluating the reproduction of the Ariki well using the parameters of the Tui well, it is possible to assume that they have the same properties as they are both in the same oil field, under the influence of the same rocks and tectonic events, under ideal conditions and hypotheses.

In general, it could be thought that two wells in the same field could make a good reproduction using the parameters found with them; however, geological and tectonic factors have a great effect, experimentally it is proven that there are differences in the reproductions using parameters determined with different oil fields and different wells, where the logs are set apart in sections whereby similarity of age and composition of the rocks should
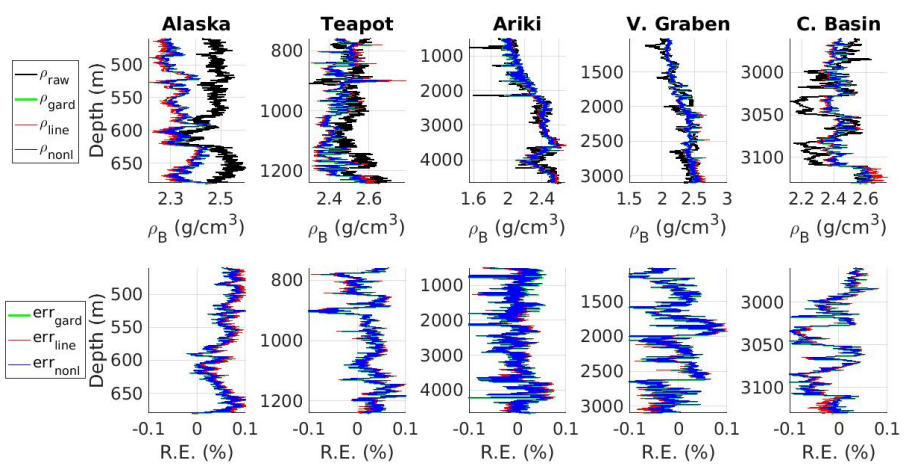

Figure 7: Reproduction of synthetic bulk density logs of each oil field, using the parameters determined for each one of them with the different linear and non-linear mathematical regressions studied in the present work.

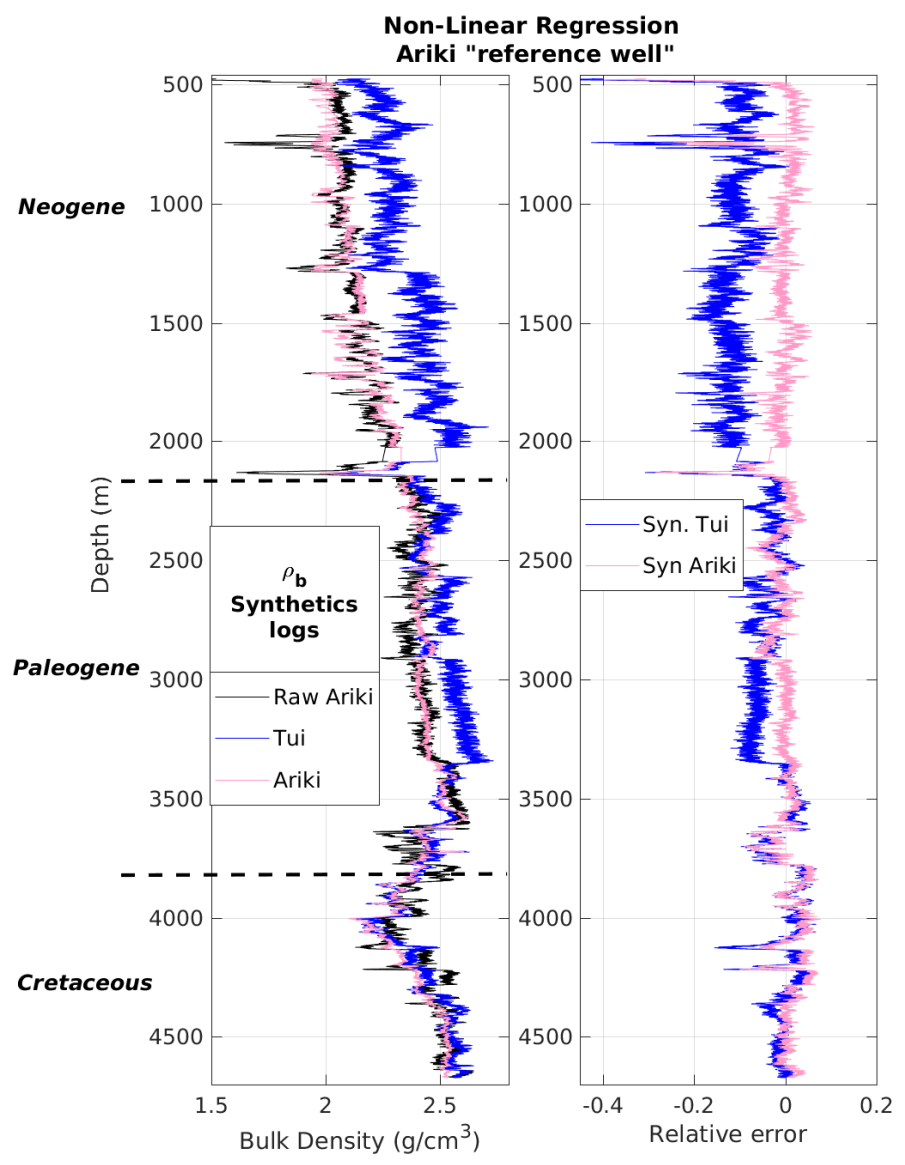

Figure 8: Synthetic bulk density logs from the Ariki well (taranaki basin oil field) using calculated parameters of the Taranaki - New Zaland (Tui and Ariki) oil fields in the nonlinear equation proposed by Oloruntobi and Butt (2019)

overlap. Analyzing the geological age interpretations on the seismic lines where the Ariki well (Figure 5) is located -exposing its location and depth of reach-, the thickness of each geological age section present is remarkable, being for each well the thickness of the geological age sections variable. The Ariki well reaches older rocks than the Tui 
well, which also shows some meteorological effects in the upper section of the bedrock that is part of the area locally explored by the well, affecting the composition of the rocks superficially and at depth through infiltration of meteoric water (Figure 5 and Figure 6).

The first two cases mentioned are remarkable on the reproduction of the synthetic log using the parameters found with the Tui well on the original log of the Ariki well, showing how the difference in thickness between age sections influences the reproduction of the parameters in such a way that it does not generate a good overpositioning of the same in the sections where there is similarity in age, which indicates that the parameters try to reproduce according to the thickness of each age interval of the rocks present in the well from which they were determined - besides intrinsically carrying their other geological characteristics and the effect of the application of corrections to the data of the well where they are found. On the other hand, the effect of tectonic and weathering on the Ariki well is the factor that generates the distance of the upper part of the synthetic log determined with Tui's parameters from the original density log of the Ariki well, taking into account that the rocks in that section are of the same age. Then, it is possible to infer that the parameters determined with the Tui well show the direct influence that tectonic, weathering and both geochemical and geoenvironmental alterations can have, which are expressed in the set of rocks present in the area around the well as shown in Figure 6 and experimentally reflected in the density log shown in Figure. 8.

The parameters obtained with the wells belonging to oil fields different from the well taken as a base, present better reproductions with a greater dispersion of data using inversion on the non-linear regression- compared to the parameters obtained with the linear methods initially evaluated, which allows greater visualization of the notable differences due to the characteristics of the rocks present in each oil field, presenting convergences with the original density log and the synthetic density log of the Ariki well in sections with age similarity. It is also possible to observe how between synthetic density logs overlaps are generated when rocks of the same age are present; however, distances are also generated due to the other factors and characteristics of the rocks in each field, influencing the estimates of each group of parameters, and likewise, establishing in each reproduction its intrinsic characteristics and generating the remarkable differences, as shown in Figure. 3.

It is also important to highlight that the values for the parameters within the non-linear model proposed by Oloruntobi and Butt (2019) do not manage to generate an optimal estimate of Ariki's density log (green synthetic curve in Figure 3), overlapping the original Ariki log (black curve) only in the section where the two logs share the same age, i.e., the Niger Delta parameters taken as standard by Oloruntobi and Butt (2019) for use within his non-linear model show the same behavior of the bulk density synthetic logs determined with the parameters of the other oil fields, being influenced and affected by factors specific to each field.

\section{Conclusions}

In this second stage of the investigation of the present work, the values obtained of the variables within the linear and non-linear equations studied and used for the determination of the bulk density of the rocks present in the subsoil (within the different oil fields studied) from other physical parameters, were compared and analyzed in order to observe their variation and behavior taking into account the own and intricate characteristics of the rocks according to their location and their immediate effect on the results obtained, which leads to the conclusion:

1) The bulk density logs reproduced using the parameters found using inversion on the non-linear regression model generate greater distribution and control of data, exposing more clearly the characteristics of each oil field and the rocks present in them (geology, tectonics, mineral composition, weathering, stratification, age, nonconformities and so on), compared to the results obtained using the parameters determined with linear models to obtain the bulk density.

2) Observing the influence of the characteristics and property of the rocks on the parameters and their ability to reproduce bulk density logs, it is clear that the geological conditions in general change at both regional and local levels, which does not provide accuracy in the reproduction of synthetic density logs using parameters determined with wells from the same field, however, if it can generate reproductions with an error less than $5 \%$ which is considered acceptable.

3) However, even if a well is evaluated with parameters obtained from another well that is similar in age and also belongs to an external field, the other characteristics of the rocks, such as composition, stratigraphic, tectonic, geo-environmental and other characteristics, generate an intrinsic effect on the parameters and therefore affect their reproduction on the bulk density log, which means that the log obtained will give a poor overlap to the original bulk density log and unreliable data when applying these parameters.

4) It is not possible to guarantee that a standard value for the parameters in both linear and non-linear mathematical models that serve at a general level for the estimation of a bulk density log in any oil field (without taking into account characteristics and properties of the rocks in each oil field), will guarantee a reproduction with high reliability in the results and a small and/or admissible margin of error.

5) According to the results of this study, it is advisable that when using the non-linear model for the estimation of the bulk density proposed by Oloruntobi and Butt (2019) for the determination of the bulk density log, the optimal parameters are determined according to the field to which the well to which the bulk density log belongs, using the well's own information -or other wells in the same field-, to guarantee a lower percentage of error, a higher reproduction, and reliability in the results.

6) The results of this study -both in the first and second part- are not limited only to research and exploratory studies in relation to petrophysics, but are also useful to apply them to studies in other branches of geophysics such as gravimetry for example (using inversion), giving a 
broader character to the usefulness of this work for future studies.

\section{Acknowledgment}

The authors also would like to thank CAPES, INCT-GP and CNPq from Brazil and the graduate program at Federal University of Pará for the financial support in this research.

\section{Bibliography}

Akimova, E. N., and V. E. Misilov, 2020, Efficient numerical algorithm for solving the gravimetry problem of finding a lateral density in a layer: Parallel implementation: Mathematical Methods in the Applied Sciences, 43, 7774-7787.

Brocher, T. M., 2008, Key elements of regional seismic velocity models for long period ground motion simulations: Journal of Seismology, 12, 217-221.

Carrasquilla, M., C. Carvalho, M. Costa, I. Souza, C. Amanajas, J. de Figueiredo, C. Silva, R. Lima, R. Silveira, and L. Rautino, 2020, Geological, geochronological and mathematical analysis of synthetic bulk density logs around the world- part ii- the use of non-linear regression on empirical parameters estimation.

de Macedo, I. A. S., J. J. S. de Figueiredo, and M. C. de Sousa, 2019, Density log correction for borehole effects and its impact on well-to-seismic tie: Application on a north sea data set: Interpretation, 8, T43-T53.

Fraser, G., D. Ellis, and S. Eggins, 1997, Zirconium abundance in granulite-facies minerals, with implications for zircon geochronology in high-grade rocks: Geology, 25, 607-610.

Gardner, G., L. Gardner, and A. Gregory, 1974a, Formation velocity and density-the diagnostic basics for stratigraphic traps: Geophysics, 39, 770-780.

— 1974b, Formation velocity and density-the diagnostic basics for stratigraphic traps: Geophysics, 39, 770-780.

Han, D.-h., A. Nur, and D. Morgan, 1986, Effects of porosity and clay content on wave velocities in sandstones: Geophysics, 51, 2093-2107.

Levenberg, K., 1944, A method for the solution of certain non-linear problems in least squares: Quarterly of applied mathematics, 2, 164-168.

Lindseth, R. O., 1979, Synthetic sonic logs-a process for stratigraphic interpretation: Geophysics, 44, 3-26.

Marquardt, D. W., 1963, An algorithm for least-squares estimation of nonlinear parameters: Journal of the society for Industrial and Applied Mathematics, 11, 431441.

Oloruntobi, O., and S. Butt, 2019, The new formation bulk density predictions for siliciclastic rocks: Journal of Petroleum Science and Engineering, 180, 526-537.

Strong, Wilson, H. K., B. G., et al., 2012, Taranaki basin, @BOOKLET. 